\title{
Efeitos do diluidor na viabilidade espermática pós-criopreservação em tourinhos da raça Gir Leiteiro aos 25 meses de idade, pré-selecionados pela classificação andrológica por pontos
}

\author{
[Effects of the extender in the semen post - thaw viability in young dairy Gyr bulls (Bos taurus indicus), \\ pre - selected by breeding soundness evaluation] \\ A.S. Felipe-Silva ${ }^{1}$, V.R. Vale Filho ${ }^{1}$, M.B.D. Ferreira ${ }^{2}$, G.S.S. Correa ${ }^{1}$, M.A. Silva ${ }^{1}$, \\ M.M. Veras $^{3}$, V.J.Andrade ${ }^{1}$ \\ ${ }^{1}$ Escola de Veterinária - UFMG \\ Av. Antonio Carlos, 6627 \\ 31270-901 - Belo Horizonte, MG \\ ${ }^{2}$ Empresa de Pesquisa Agropecuária de Minas Gerais - Uberaba, MG. \\ ${ }^{3}$ Faculdade de Medicina - USP - São Paulo, SP
}

\begin{abstract}
RESUMO
Procedeu-se à criopreservação do sêmen de oito tourinhos Gir Leiteiro, com idade média de 25 meses, pré-selecionados para elevada pontuação (média $84,4 \pm 5,6$ ) na classificação andrológica por pontos (CAP), em dois diferentes diluidores: um à base de lactose-gema-glicerol e outro à base de lecitina de soja. As curvas de resfriamento e congelação foram padronizadas com o auxílio da máquina CRYOGEN $^{\circledR}$. Os parâmetros pós-congelação avaliados no sêmen submetido aos dois diluidores motilidade, vigor, defeitos maiores, menores e totais, defeitos de acrossoma, cauda dobrada, reação ao teste hiposmótico (Thos) e células normais - foram comparados aos do sêmen fresco, exceto para Thos e entre eles. O sêmen de todos os animais foi congelado com êxito no diluidor lactose-gema-glicerol. Houve diferença $(\mathrm{P}<0,05)$ em todas as variáveis analisadas no sêmen fresco e pós-congelado, exceto para defeitos maiores. Entre diluidores, houve diferença $(\mathrm{P}<0,05)$ para motilidade, vigor, cauda dobrada e Thos. Estes resultados indicam que a seleção pelo CAP médio >80 é um bom índice para selecionar touros com maior taxa de espermatozoides viáveis pós-congelação.
\end{abstract}

Palavras-chave: touro Gir leiteiro, sêmen, congelação, diluidor, CAP

\begin{abstract}
Semen cryopreservation from eight young dairy Gyr bulls was performed using two different semen extenders. Bulls aging 25 months old and pre-selected for a high average score (84.4 \pm 5.6 in a 0-100 scale) in Zebu breeding soundness evaluation (BSE) composed the experimental group. Extenders were based on lactosis-egg yolk-glycerol and soya lecithin. Chilling and freezing curves were standardized by CRYOGEN ${ }^{\circledR}$ machine. Post-thaw features evaluated in semen frost in both extenders - motility, vigor, major, minor and total deffects, morphological alteration in acrossome, bent tail, reative cells to hyposmotic sweeling test (Thos), and normal cells - were compared to the ones in the fresh ejaculate (except Thos) and among them. It was possible to freeze semen from all animals in the lactosis-egg yolkglycerol extender. There were difference $(P<0.05)$ in all analyzed features between fresh and cryopreserved semen, except for major deffects. Between extenders, there were differences $(P<0.05)$ in motility, vigor, bent tail, and Thos. All bulls had successfull semen freezability. These results sustain that pre-selection for high BSE values (average $>80$ points) is a good index to identify bulls with good post semen - thaw features. However, the choice of the extender is critical for obtaining acceptable results.
\end{abstract}

Keywords: dairy Gyr bull, semen, freezability, extender, BSE

Recebido em 17 de junho de 2009

Aceito em 10 de janeiro de 2011

Email: anibalfelipe@yahoo.com 


\section{INTRODUÇÃO}

A inseminação artificial com sêmen criopreservado é ferramenta comum na atividade pecuária contemporânea. Entretanto, a criopreservação é prejudicial à função espermática e à fertilidade, danificando seriamente cerca de $50 \%$ dos espermatozoides. A predição desses danos, pré-congelação, permanece incerta. As técnicas correntes para criopreservação continuam a induzir efeitos deletérios na qualidade espermática após a descongelação. Por exemplo, uma queda significativa na motilidade espermática é universalmente aceita como consequência da criopreservação em touros (Watson, 1995).

As raças zebuínas e seus cruzamentos apresentam grande importância na composição da pecuária brasileira, representando cerca de 80\% do efetivo bovino nacional (Cartaxo et al., 2001). Nessas raças ou grupos genéticos, surge a necessidade de se estabelecerem rígidos critérios de seleção para a melhoria da fertilidade da raça, por meio de alta pressão de seleção sobre a qualidade seminal dos touros, principalmente na raça Gir Leiteiro, que respondeu por $58,1 \%$, ou 803.411 doses, quando apenas se contabilizaram as doses de sêmen de raças com aptidão leiteira produzidas no país (Relatório ..., 2008).

No sistema proposto por Vale Filho (1989) para avaliação andrológica de touros zebuínos, denominado pela classificação andrológica por pontos (CAP), são pontuados os valores obtidos nas mensurações da circunferência escrotal (CE), da morfologia e da motilidade espermáticas, em função da idade do animal, com valores máximos de 40, 40 e 20, respectivamente. Segundo o autor, as idades nas avaliações de Bos taurus indicus devem ser consideradas como o dobro das apontadas no CAP para Bos taurus taurus (Chenoweth e Ball, 1980). Vale Filho et al. (1999) estimaram valores de correlações entre CAP e motilidade, vigor e turbilhonamento espermáticos, volume do ejaculado, defeitos maiores, menores e totais dos espermatozoides e peso corporal, respectivamente de: 0,$51 ; 0,12$; 0,$16 ; 0,71 ; 0,31 ; 0,26 ; 0,43$ e 0,32 .

Em padrões pré-definidos de congelação estabelecidos por uma central de inseminação artificial, em São Paulo, Roncolleta et al. (1999), ao investigarem 10 touros da raça Gir Leiteiro, identificaram, em análise eletroforética do tipo
SDS-PAGE, uma banda relacionada a uma proteína no grupo de alta congelabilidade acima de $80 \%$ dos ejaculados viáveis, pósdescongelação.

Os constituintes básicos dos diluidores são substâncias energéticas, crioprotetores, soluções tampões e antibióticos (Holt, 2000; Celeghini, 2005). O glicerol e várias lipoproteínas da gema do ovo têm sido os crioprotetores normalmente utilizados na criopreservação do sêmen de touros há vários anos. No entanto, há algum tempo novos diluidores com componentes crioprotetores baseados em lecitina vêm sendo colocados em prática (Gil et al., 2000; van Wagtendonk-Leeuw et al., 2000; Aires et al., 2003). O principal motivo para essa substituição seria a possibilidade de veiculação de doenças causadas por bactérias e por micoplasmas (Bousseau et al., 1998; van Wagtendonk-Leeuw et al., 2000).

O objetivo deste experimento foi buscar a associação da CAP com a taxa de recuperação espermática pós-congelação, testando-se diluidores tradicionais que contêm gema de ovolactose-glicerol e alternativos, livres da gema de ovo, substituída, dentre outros pela lecitina de soja.

\section{MATERIAL E MÉTODOS}

O estudo foi desenvolvido em outubro de 2006, na Fazenda Experimental Getúlio Vargas, unidade de pesquisa da EPAMIG, localizada no município de Uberaba, MG, com tourinhos produzidos pela própria fazenda, com média de idade de 25,0 meses e confinados desde o mês de julho do mesmo ano.

Oito tourinhos Gir Leiteiro, confinados sob dieta total desde os 22 meses de idade, foram selecionados dentre 22 animais de um grupo de contemporâneos para o teste de congelamento, considerando-se a qualidade física e/ou morfológica do sêmen e o valor da CAP média do grupo (CAP> 80). Utilizaram-se dois diferentes diluidores seminais: um tradicional, baseado em gema de ovo-lactose-glicerol (Nagase e Niwa, 1964), e outro comercial Bioxcell $^{\circledR}$ (IMV, IVP, Brasil). As curvas de resfriamento e congelação foram padronizadas com o auxílio da máquina CRYOGEN ${ }^{\circledR}$ (NEOVET, Uberaba, Brasil). Para a coleta de sêmen, adotou-se o método da eletroejaculação, 
com esvaziamento prévio do reto e massagem manual das glândulas anexas.

Imediatamente após a ejaculação, realizou-se a avaliação, em microscópio óptico, aumento de 100X, do turbilhonamento, da motilidade e do vigor. O turbilhonamento foi expresso numa escala de um a cinco, a motilidade foi expressa como percentual de espermatozoides móveis e o vigor foi classificado segundo uma escala de zero a cinco, em que zero caracteriza ausência de movimentos, e cinco o movimento vigoroso e veloz dos espermatozoides (Manual..., 1998). Os valores obtidos para as características físicas de motilidade e vigor (pré-congelação) foram utilizados como referência para os valores obtidos pós-descongelação. Para as análises morfológicas do sêmen, alíquotas do ejaculado foram acondicionadas em microtubos que continham 1mL de solução formol-salina tamponada (Hancock, 1957) e levadas ao laboratório para visualização, sob microscopia de contraste de fase, e quantificação das porcentagens de espermatozoides normais, com defeitos maiores, com defeitos menores e total de defeitos, de acordo com a metodologia descrita por Blom (1973).

Para ser congelado, o sêmen foi diluído em temperatura ambiente $\left(30^{\circ} \mathrm{C}\right)$, a fim de estabelecer a concentração pós-diluição de $30 \times 10^{6}$ espermatozoides por dose inseminante, e obter, no máximo, 20 palhetas de $0,5 \mathrm{~mL}$ por tourinho. As palhetas previamente identificadas foram envasadas, lacradas com álcool polivinílico e inseridas na máquina CRYOGEN, onde foram refrigeradas lentamente até $5^{\circ} \mathrm{C}$, para um período de estabilização mínimo de quatro e máximo de seis horas. Em seguida, procedeu-se a curva padronizada de congelação com taxa de queda média da temperatura de $0,26^{\circ} \mathrm{C} /$ segundo, até o tempo total de 8' 45', Após atingirem a temperatura de $-135^{\circ} \mathrm{C}$, as palhetas foram removidas da máquina e imediatamente mergulhadas em nitrogênio líquido, a $-196^{\circ} \mathrm{C}$.

A metodologia para o teste hiposmótico (Thos) consistiu na elaboração de uma mistura de $20 \mu \mathrm{L}$ de sêmen em $200 \mu \mathrm{L}$ de uma solução contendo citrato de sódio e frutose, a $100 \mathrm{mOsmol} / \mathrm{mL}$, mantida a $37^{\circ} \mathrm{C}$ por uma hora em banho-maria. Após este período, as amostras de sêmen criopreservado foram fixadas em $0,2 \mathrm{~mL}$ de solução formol-salina tamponada para leitura em microscopia de contraste de fase, sendo o número total de caudas dobradas aferidas após o teste subtraído do número de caudas dobradas obtidas antes da incubação em solução hiposmótica (Correa et al., 1997; Melo, 1999). O resultado obtido foi tomado como o percentual de espermatozoides reativos com membrana espermática funcional.

Valores de motilidade, vigor, defeitos maiores, menores e totais, defeitos de acrossoma, cauda dobrada, reação ao Thos e células normais, obtidos com os dois diferentes diluidores, sob a mesma curva de congelação, foram avaliados e comparados aos do sêmen fresco (exceto Thos) utilizando-se análises de variância e teste SNK do pacote estatístico SAEG (Sistema..., 2001).

\section{RESULTADOS E DISCUSSÃO}

Na Tab. 1, mostram-se os valores das características do sêmen antes e após congelação, com ambos os diluidores, exceto defeitos maiores. Entende-se que a alta qualidade do sêmen dos tourinhos, com mínimos níveis de deficiência na gametogênese, representada pela reduzida porcentagem de defeitos maiores, foi responsável pela não diferença para esse parâmetro avaliado isoladamente. Para todas as outras variáveis, no entanto, houve diferença $(\mathrm{P}<0,05)$ entre o sêmen fresco e o pós-congelado.

Quando se comparou a eficiência dos dois diluidores em manter a viabilidade dos espermatozoides pós-congelação, o diluidor proposto por Nagase e Niwa (1964) foi mais eficiente que 0 diluidor Bioxcell $^{\circledR}$ para motilidade, 37,5\% x 13,7\%; vigor, 3,56 x 1,81; cauda dobrada, $10,7 \%$ x 14,7; e espermatozoides reagentes ao teste hiposmótico, 75,7\% x 72,12\%. Evidenciou-se, portanto, melhor funcionalidade das células espermáticas criopreservadas no diluidor tradicional, mais barato e também de fácil manipulação. Resultados também significativos para valores de motilidade póscongelação, utilizando-se diluidores à base de gema de ovo, também foram encontrados por Aboagla e Terada (2004). Contudo, Aires et al. (2003) encontraram valores mais baixos de motilidade para o sêmen criopreservado em TRIS-gema, quando comparado com um diluidor comercial à base de lecitina de soja $(\mathrm{P}<0,05)$, sem diferenças, no entanto, para os testes de adesão à zona pelúcida e reação acrossômica induzida $(\mathrm{P}>0,05)$. 
Felipe-Silva et al.

Tabela 1. Características do sêmen de oito machos jovens da raça Gir Leiteiro, com idade média de 25 meses

\begin{tabular}{|c|c|c|c|c|c|c|c|c|c|}
\hline \multicolumn{10}{|c|}{ Característica seminal } \\
\hline Condição do ejaculado & $\begin{array}{l}\text { Mot } \\
(\%)\end{array}$ & $\begin{array}{c}\text { Vig } \\
(1-5)\end{array}$ & $\begin{array}{l}\mathrm{DM} \\
(\%)\end{array}$ & $\begin{array}{l}\mathrm{Dm} \\
(\%)\end{array}$ & $\begin{array}{l}\text { DT } \\
(\%)\end{array}$ & $\begin{array}{c}\text { Acros } \\
(\%)\end{array}$ & $\begin{array}{l}\text { Cdob } \\
(\%)\end{array}$ & $\begin{array}{l}\text { Thos } \\
(\%)\end{array}$ & $\begin{array}{c}\text { Normai } \\
\mathrm{s}(\%)\end{array}$ \\
\hline Sêmen fresco & $66.87 a$ & $4,62 \mathrm{a}$ & $\begin{array}{c}10,7 \\
5 \\
10,2\end{array}$ & $6,62 \mathrm{a}$ & $17,37 a$ & $1,25 a$ & $2,37 a$ & ---- & $82,62 a$ \\
\hline $\begin{array}{l}\text { Pós-congelação em Nagase } \\
\text { Pós-congelação em }\end{array}$ & $37,50 \mathrm{~b}$ & $3,56 b$ & $\begin{array}{c}5 \\
10,8\end{array}$ & $14,00 \mathrm{~b}$ & $24,25 b$ & $4,87 \mathrm{~b}$ & $10,75 b$ & $37,62 \mathrm{a}$ & $75,75 b$ \\
\hline Bioxcell $\AA$ & $13,75 c$ & $1,81 \mathrm{c}$ & 7 & $17,00 \mathrm{~b}$ & $27,87 \mathrm{~b}$ & $4,37 \mathrm{~b}$ & $14,75 c$ & $16,62 b$ & $72,12 b$ \\
\hline
\end{tabular}

Mot: motilidade; Vig: vigor; Turb: turbilhonamento; DM: defeitos maiores; Dm: defeitos menores; DT: defeitos totais; Acros: defeitos de acrossoma; Cdob: cauda dobrada; Thos: espermatozoides reagentes ao teste hiposmótico.

Letras diferentes na mesma coluna indicam diferença entre valores, pela análise de variância $(\mathrm{P}<0,05)$.

Para a característica não paramétrica vigor (Vig), foi utilizado o teste Kruskal-Wallis $(\mathrm{P}<0,05)$.

Neste estudo, não houve diferença entre diluidores para defeitos menores, defeitos totais, defeitos de acrossoma e porcentagem de espermatozoides normais $(\mathrm{P}>0,05)$. Aboagla e Terada (2004), ao trabalharem com sêmen caprino, encontraram valores mais baixos $(\mathrm{P}<0,05)$ para lesões de acrossoma em diluidores que não continham gema de ovo, principalmente os que continham trealose como base. No entanto, ao avaliarem, separadamente, os efeitos do glicerol e da gema de ovo associados ao TRIS, não encontraram diferença $(\mathrm{P}<0,05)$ na porcentagem de defeitos de acrossoma. Para a associação de gema de ovo e glicerol, contudo, obtiveram maior porcentagem $(\mathrm{P}<0,05)$ de lesões de acrossoma. Jones e Martin (1973), ao trabalharem com sêmen de carneiros, demonstraram que a gema de ovo foi eficiente em preservar as características ultraestruturais dos espermatozoides, especialmente as do acrossoma.

Observou-se no teste hiposmótico maior porcentagem $(\mathrm{P}<0,05)$ de espermatozoides reativos pós-congelação com o uso do diluidor Nagase (37,6\%) do que com o diluidor Bioxcell ${ }^{\circledR}$ $(16,6 \%)$. Tal fato demonstra que as células crioprotegidas pelo primeiro diluidor sofreram menor taxa de ruptura de membranas espermáticas, portanto apresentaram maior viabilidade pós-congelação efetiva e melhores perspectivas em relação à fertilização do oócito (Jeyendran et al., 1984). Os resultados do Thos evidenciaram sua associação com motilidade e vigor espermáticos pós-congelação, o que aumenta sua importância como teste funcional complementar a ser utilizado, pelo menos em centrais de inseminação artificial, e, de maneira análoga, ratifica a importância da motilidade e do vigor pós-congelação como indicadores do poder fecundante do sêmen (Casagrande et al., 1979; Vale Filho, 1989; Manual..., 1998).

O valor de CAP médio desses animais (84,4 pontos) foi elevado para a idade. Tal índice agrega informações sobre os aspectos físicos e morfológicos do sêmen (Tab. 2) e, ainda, de medidas de circunferência escrotal de touros zebus, em função da idade. Uma vez que essa avaliação apresenta-se como a mais rigorosa do país, valorizando indivíduos precoces e de espermatogênese perfeita, somente se utilizaram animais que ofereceram padrão de sêmen mais alto para a comparação da congelabilidade entre os dois diluidores empregados.

Os resultados obtidos sugerem que os ejaculados de bovinos jovens da raça Gir Leiteiro encontram melhor estabilidade com o diluidor Nagase, seja pela maior taxa de glicerol e de lactose, seja pelas características das macromoléculas da gema do ovo em relação às macromoléculas presentes no Bioxcell ${ }^{\circledR}$, ou ainda por uma associação desses e de outros fatores que não foram controlados neste experimento. Foi demonstrado que houve melhor resposta do sêmen diluído em Nagase ao processo de congelação realizado pela máquina CRYOGEN ${ }^{\circledR}$ e, ainda, melhor interação entre esse diluidor e o sêmen dos animais Gir Leiteiro, aos 25 meses de idade. 
Efeitos do diluidor na viabilidade...

Tabela 2. Classificação andrológica por pontos para touros zebuínos, baseada na circunferência escrotal e nas características do sêmen

\begin{tabular}{|c|c|c|c|c|}
\hline & Excelente & Bom & Regular & Fraco \\
\hline \multicolumn{5}{|l|}{ Motilidade espermática } \\
\hline De massa (1-5) & Vigor 5 & Vigor 4-5 & Vigor 4 & Vigor $3(0-3)$ \\
\hline Individual (\%) & Acima $70 \%$ & $60-69 \%$ & $50-59 \%$ & Abaixo 50\% \\
\hline Total de pontos & 20 & 12 & 10 & 3 \\
\hline \multicolumn{5}{|l|}{ Morfologia espermática } \\
\hline Defeitos maiores & Abaixo 10\% & $10-19 \%$ & $20-29 \%$ & Acima 29\% \\
\hline Total de defeitos & Abaixo 25\% & $26-39 \%$ & $40-59 \%$ & Acima 59\% \\
\hline Total de pontos & 40 & 25 & 10 & 3 \\
\hline \multicolumn{5}{|l|}{$\begin{array}{l}\text { Circunferência escrotal } \\
\text { Idade (meses) }\end{array}$} \\
\hline $18-23$ & Acima 30 & $26-30 \mathrm{~cm}$ & Abaixo 26 & Abaixo $26 \mathrm{~cm}$ \\
\hline $24-30$ & Acima 34 & $30-34 \mathrm{~cm}$ & Abaixo 30 & Abaixo $30 \mathrm{~cm}$ \\
\hline $31-40$ & Acima 36 & $31-36 \mathrm{~cm}$ & Abaixo 31 & Abaixo $31 \mathrm{~cm}$ \\
\hline $41-60$ & Acima 38 & $32-38 \mathrm{~cm}$ & Abaixo 32 & Abaixo $32 \mathrm{~cm}$ \\
\hline$>60$ & Acima 39 & $34-39 \mathrm{~cm}$ & Abaixo 34 & Abaixo $34 \mathrm{~cm}$ \\
\hline Total de pontos & 40 & 24 & 10 & 10 \\
\hline
\end{tabular}

Adaptado de Vale Filho (1989).

Com relação às normas estabelecidas pelo CBRA (Manual..., 1998) para características físicas do sêmen congelado, motilidade $(>30 \%)$ e vigor $(>3,0)$, todas as doses criopreservadas em Nagase (100\%) foram aprovadas e estão aptas a serem empregadas em inseminação artificial no campo ou em outros processos biotecnológicos da reprodução. Ao contrário, nenhuma dose criopreservada com Bioxcell ${ }^{\circledR}$, nas mesmas condições experimentais, obteve o mesmo êxito.

\section{CONCLUSÕES}

A seleção para CAP >80 pontos foi eficiente como marcador para a obtenção de excelentes taxas de recuperação pós-congelação (100\% de doses viáveis), quando se utilizou o diluidor à base de lactose-gema-glicerol. Ao contrário, quando da utilização do diluidor à base de lecitina de soja, as taxas de recuperação foram significativamente menores. Existe influência do diluidor sobre a qualidade do sêmen póscongelação, e sua escolha tem o objetivo de maximizar a produção de doses viáveis por animal e de reduzir os custos. O teste hiposmótico ratificou os achados pós-congelação obtidos para motilidade, vigor e porcentagem de caudas dobradas, apresentando-se como ferramenta eficaz e de baixo custo para identificação da taxa de células com membranas espermáticas funcionalmente prejudicadas pelo processo de criopreservação.

\section{REFERÊNCIAS BIBLIOGRÁFICAS}

ABOAGLA, E.M.E.; TERADA, T. Effects of egg yolk during the freezing step of cryopreservation on the viability of goat spermatozoa. Theriogenology, v.62, p.11601172, 2004.

AIRES, V.A.; HINSCH, K.D.; MÜLLERSCHLÖSSER, F. et al. In vitro and in vivo comparison of egg yolk-based and soybean lecithin-based extenders for cryopreservation of bovine semen. Theriogenology, v.60, p.269, 2003.

BLOM, E. The ultrastructure of some characteristic sperm defects and a proposal for a new classification of the bull spermiogram. Nord. Vet. Med., v.25, p.383-391, 1973.

BOUSSEAU, S.; BRILLARD, .P.; MARQUANT-LE GUIENNE, B. et al. Comparison of bacteriological qualities of various egg yolk sources and the in vitro and in vivo fertilizing potential of bovine semen frozen in egg yolk or lecithin based diluents. Theriogenology, v.50, p.699-706, 1998.

CARTAXO, W.O.; PENA-ALFARO, C.E.; BACALHAU, A. et al. Parâmetros seminais e circunferência escrotal de touros jovens da raça Guzerá criados no estado da Paraíba. Rev. Bras. Reprod. Anim., v.25, p.214-215, 2001. 
CASAGRANDE, J.F.; PINHEIRO, L.E.L.; ALMEIDA, A.C. et al. A influência da motilidade e da velocidade espermática sobre a fertilidade do sêmen. Rev. Bras. Reprod. Anim., v.3, p.31-35, 1979.

CELEGHINI, E.C.C.; NASCIMENTO, J.; RAPHAEL, C.F. et al. Simultaneous assessment of plasmatic, acrosomal, and mitochondrial membranes in ram sperm by fluorescent probes. Arq. Bras. Med. Vet. Zootec., v.62, p.536-543, 2010.

CHENOWETH, P.J.; BALL, L. Breeding soundness evaluation in bulls. In: MORROW, D.A. (Ed). Current therapy in theriogenology. Philadelphia: W.B. Saunders, 1980. p.330-339.

CORREA, J.R.; PACE, M.M.; ZAVOS, P.M. Relationship among frozen-thawed sperm characteristics assessed via the routine semen analysis, sperm functional tests and fertility of bulls in an artificial insemination program. Theriogenology, v.48, p.721-731, 1997.

GIL, J.; JANUSKAUSKAS , A.; HAARD, M. et al. Functional sperm parameters and fertility of bull semen extended in Biociphos-Plus and Triladyl. Reprod. Dom. Anim., v.35, p.69-77, 2000.

HANCOCK, J.L. The morphology of boar spermatozoa. J. Royal Microsc. Soc., v.76, p.8497, 1957.

HOLT, W.V. Basic aspects of frozen storage of semen. Anim. Reprod. Sci., v.62, p.3-22, 2000.

JEYENDRAN, R.S.; VAN DER VEN, H.H.; PEREZ-PELAEZ, M. et al. Development of an assay to asses the human sperm membrane and its relationship to other semen characteristics. $J$. Reprod. Fertil., v.70, p.219-228, 1984.

JONES, R.C.; MARTIN, I.C.A. The effects of dilution, egg yolk and cooling to $5^{\circ} \mathrm{C}$ in the ultrastructure of ram spermatozoa. J. Reprod. Fertil., v.35, p.311-320, 1973.

MANUAL para exame andrológico e avaliação de sêmen animal. 2.ed. Belo Horizonte: CBRA, 1998. 49p.

MELO, M.I.V. Teste hiposmótico na avaliação do sêmen equino. 1999. 67f. Dissertação (Mestrado) - Escola de Veterinária, Universidade Federal de Minas Gerais, Belo Horizonte.
NAGASE, H.; NIWA, T. Deep freezing of bull semen. Factors affecting survival of spermatozoa. In: INTERNATIONAL CONGRESS ON ANIMAL REPRODUCTION, 5., 1964, Trento. Proceedings... Trento: ICAR, 1964. v.4, p.410-415.

RELATÓRIO estatístico de produção, importação e comercialização de sêmen. Uberaba: Associação Brasileira de Inseminação Artificial, 2008. Disponível em: $<$ http://www.asbia.org.br/download/mercado/rela torio2008.pdf $>$. Acessado em: 16 jun. 2009.

RONCOLETTA, M.; FRANCESCHINI, P. H.; LIMA, V.F.M.H. et al. Perfil em SDS-PAGE das proteínas do plasma seminal e sua relação com a congelabilidade do sêmen de touros doadores da raça gir. Braz. J. Vet. Res. Anim. Sci., v.36, p.8286, 1999.

SISTEMA de análises estatísticas SAEG.Viçosa: UFV, 2001.

VALE FILHO, V.R. Padrões de sêmen bovino, para o Brasil. Análise e sugestões. In: CONGRESSO BRASILEIRO DE REPRODUÇÃO ANIMAL, 8., 1989, Belo Horizonte. Anais... Belo Horizonte: CBRA, 1989. p.94-118.

VALE FILHO, V.R.; QUIRINO, C.R.; ANDRADE, V.J. et al. Parâmetros genéticos da classificação andrológica por pontos (CAP), em touros da raça Nelore. Rev. Bras. Reprod. Anim., v.23, p.253-255, 1999.

VAN WAGTENDONK-LEEUW, A.M.; HARING, R.M.; KAAL-LANDSBERGEN, L. M.T.E. et al. Fertility results using bovine semen cryopreserved with extenders based on egg yolk and soybean extract. Theriogenology, v.54, p.5767, 2000.

WATSON, P.F. Recent developments and concepts in the cryopreservation of spermatozoa and the assessment of their post-thawing function. Reprod. Fertil. Dev., v.7, p.871-891, 1995. 